\title{
Analysis of Mobile Phone Technology Usage in Farmer Situation: The Case of Sodo Zuria District, Wolaita Zone, Southern Nation Nationalities and Peoples' Region, Ethiopia
}

\author{
Michael Heliso, Sundaraa Rajan \\ Department of Rural Development and Agricultural Extension, College of Agriculture, Wolaita Sodo University, \\ Wolaita Sodo Ethiopia
}

*Corresponding Author: Michael Heliso, Department of Rural Development and Agricultural Extension, College of Agriculture, Wolaita Sodo University, Wolaita Sodo Ethiopia

\begin{abstract}
Any analysis on mobile phone technology usage has been given due emphasis on the understanding of the context within the people, the potential assets endowed among the people, the strategies followed by them in the face of existing policies and institutions, and livelihood outcomes that were intended to be achieved. The sustainability of livelihood in farming households is not yet a fully achieved agenda in developing Countries like Ethiopia. Most of the farming households in Soddo Zuria District in Wolaita Zone remain vulnerable to various man-made and natural shocks due to the fact that Soddo Zuria district was declared by the government as one of food insecure districts at national level. These facts initiated the researcher to conduct this research in the district under discussion. Having the general objective of analyzing the present scenario of mobile phone technology usage in farming HHs in the study area as mobile phone technology users and non-users that was analyzed through three specific objectives viz.to assess the current status of mobile phone usage by farmers in the study area, to find out factors that influence mobile phone usage of farmers in the study area, and find out the current alternative usage to mobile technology in the study area.120 household heads were selected from three different kebles in Sodo Zuriaworedabased on availability of electricity and basic ICT infrastructure. The samples were selected by PPS through simple random sampling method and the quantitative data were collected by using semi-structured interview schedule while the qualitative data were collected by using a check-list for Focus Group Discussions and Personal Interviews. The quantitative data analysis was done by application of descriptive and inferential statistics and the significance of every explanatory variable upon the dependent variable was tested by binominal logit model. Out of the 19 independent variables used in this study the following independent variables affected the livelihood strategies adopted by the sample units in different probability levels (less than 1\%,5\% and 10\%). They were: age of household, the family size, farm size, mobile phone use training, annual Income of HHs, cost of mobile, achievement motivation and information seeking behavior. Therefore, the study calls for provision of stable services by mobile telecommunications service providers, regular electric power supply, training of the farmers by extension agents and agricultural development agencies as well as formation of agricultural societies by the farmers.
\end{abstract}

Keywords: Constraints, mobile phone, technology, farmers, telecommunication, Variables.

\section{INTRODUCTION}

The dissemination of information and communication technologies (ICTs) in developing countries provides much opportunity to transfer knowledge and information by private companies and government departments. In the last many years mobile phone coverage has spread fast in Asian, African and Latin American countries. It was indicated that more than sixty per cent of the population of sub-Saharan Africa, Asia and Latin America had access to mobile phone coverage in 2009. In the past the adoption of the mobile phones was primarily by rich people residing in urban areas. Nowadays mobile phones have been adopted by rural and urban populations in developing countries who are getting a good benefit and latest information regarding weather, market and other related issues (Aker \& Mbiti, 2010).

A mobile phone (also known as a cellular phone, cell phone, and a hand phone) is a device that can make and receive telephone calls over a radio link while moving around a wide geographic area. It does so by connecting to a cellular network provided by a mobile phone operator, allowing access to 
the public telephone network. By contrast, a cordless telephone is used only within the short range of a single, private base station. Nowadays it has become the world's most common way of transmitting voice, data, and services, and no technology has ever spread faster. At the end of 2010 there were 5.25 billion cellular telephone subscriptions worldwide. That is equivalent to 96 percent of the world population and is a huge increase from 6.0 billion mobile subscribes in 2011 and 5.4 billion in 2010(ITU, 2009).

Mobile phones significantly have reduced communication and information costs for the rural people. This technology has provided new opportunities for rural farmers to obtain knowledge and information about agricultural issues, problems and its usage for the development of agriculture. Similarly, use of ICTs in agricultural extension services especially mobile phone services in the agricultural sector has provided information on market, weather, transport and agricultural techniques to contact with concern agencies and department (Aker, 2011).

The rural community especially farmers were facing many problems, obstacles and challenge in the use of ICT tools such as mobile phones. There were many challenges were indicated such as organizational, technical, financial, social and illiteracy. In the terms of organizational factor the lack of interest by higher authorities and extension experts to use ICT tools were also observed. However, the low quality of services provided by the companies and lack of interest by private sector to participate in developing ICT programs for rural area was big issue for the development of agriculture development in rural areas of developing countries (Hosseini et al., 2009).

The lack of knowledge was also a big problem among rural communities and farmers in use of ICT, while another study indicated in the context of Malaysia that the level of ICT usage among rural community especially farmers were low due lack knowledge and skills. The illiteracy was also a cause of use ICT among farmers because famers could not contact with related officers and department and get information about market price, weather or pesticides even farmers was not knowledge about use of mobile phone to contact with their family and friends due to illiteracy (Samuel et al., 2005).The farmers who had no access to mobile phones were facing many problems in selling their produce and getting information regarding market compare with farmers who use phone users.

Inadequate dissemination of agricultural information as result of challenges facing use of ICTs generally and mobile phone particularly will be contribute to the reduction of agricultural productivity, economic performance, food security and loss of biodiversity in Ethiopia. Ethiopian farmers experience many challenges with respect to information dissemination and accessibility of ICTs to increase their agricultural knowledge. These include lack of information and communication facilities, poor information delivery channels and low use of existing technologies. There will be the deficiency of information on the challenges facing use of ICTs to disseminate agricultural information to farmers. This study sought to help fill this gap in knowledge by conducting a survey research in the study area. Therefore, this study was assessed the present scenario with regard to mobile phone technology usage and the determinants of that mobile phone technology usage in Sodo Zuria Woreda, Wolaita Zone, SNNPR, Ethiopia

\section{RESEARCH METHODOLOGY}

In this study, both purposive (non-probability sampling) and simple random sampling techniques (probability sampling) was used to select the kebele administration and sample respondents.

In multi-stage sampling method, a sequence of sample is drawn from samples already selected but only the last sample of subjects is studied. Simple random sampling technique was used to select sample Kebele administration.

By applying multi-stage sampling technique, in the first stage, Sodo Zuria Woreda was selected purposively among 12 rural Woreda of Wolaita zone as it hosts many Agricultural Research Centers (Zonal, Regional, and Federal), University, ATVET, INGOs and LNGOs and some private agro-based companies and relatively enhances their food security. This means that the area receives a lot of new agricultural information and service from them. Among the all 31 kebeles, 3kebleswere selected purposefully because of the relative availability of electricity and the ICTs infrastructure facilities. 
Analysis of Mobile Phone Technology Usage in Farmer Situation: The Case of Sodo Zuria District, Wolaita Zone, Southern Nation Nationalities and Peoples' Region, Ethiopia

Households in the selected kebeles were stratified in to mobile phone user and non-user based on information from Soddo Zuria Agricultural and Rural Development office. In the third stage, probability proportionate sampling (PPS), respondents from each household category was selected.

Due to time and resource limitation, a sample size will be obtained from sample frame using the following formula.

$\mathrm{n}=\frac{N}{1+N(e) 2}=100$

This Yamane formula gives 100 sample units. However, to the sake of any drop outs or withdrawals of sampling units during data collection another $20 \mathrm{HHHs}$ were added. Thus, the total sampling units were $120 \mathrm{HHHs}$ for this study of which 100 are MHHHs and the 20 are FHHHs.

Table1. Sample size distribution in the sample Kebele Administrative

\begin{tabular}{|c|c|c|c|c|}
\hline Kebeles & Total mobile using & Total mobile & \multicolumn{2}{|c|}{ PPS } \\
\cline { 4 - 5 } & HHHs & Non using HHHs & Users & Non Users \\
\hline DalboAtwaro & 566 & 538 & 23 & 21 \\
\hline Gulugula & 161 & 920 & 6 & 37 \\
\hline AmachoKodo & 136 & 744 & 5 & 28 \\
\hline & 863 & 2202 & 34 & 86 \\
\hline
\end{tabular}

Source: Research Compilation, 2014

Since data gathering method is designed by for both qualitative and quantitative methods, it directs the method of data analysis. Hence the data collected by qualitative method were analyzed by qualitative method through interpretation, conceptualization and tabulation of data. The data quantitatively gathered were analyzed by descriptive and inferential statistics.

In general, this study focuses on mobile phone technology usage in farmers' situation. Several studies interlinked the area or issue with demographic, economic, psychological, institutional and socioeconomic factors. Thus, there is need to have appropriate model that can consists all dimensions of data required to come up with relevant conclusion or outcome. For deciding the model specification from the three types of model such as liner, log it and prohibit.

According to Feder et al., (1985) log it and prohibit the most frequently used when dependent variable is dichotomous. (Gujarati, 1998) indicated, the functional form of the log it model used in this study is presented as $f$ ollows

$\mathrm{Pi}=\mathrm{E}\left(\frac{Y_{i}}{x_{i}}\right)=\frac{1}{1+e^{\beta 0+\beta 1_{1}}}$

For the case of explanation we write (1) as;

$\mathrm{Pi}=\mathrm{E}\left(\frac{Y_{i}}{x_{i}}\right)=\frac{1}{1+e^{-z_{i}}}$

The probability that a given household used mobile phone is expressed by (2) while the probability of non-using mobile phone is;

$1-\mathrm{p}_{\mathrm{i}}=\frac{1}{1+e z^{i}}$

Therefore, we can write;

$\mathrm{e}^{\mathrm{zi}}=\frac{p_{i}}{1-p i}=\frac{1+e z^{i}}{1+e-z^{i}}$

Now $\left(\frac{p_{i}}{1-p i}\right)$ is simply the odds ratio in favor of using mobile phone. The ratio of probability that a household will use mobile phone to the probability of that he will not use mobile phone technology.

Finally, taking the natural $\log$ of the equation (4) we obtain;

$\mathrm{Li}=\ln \left(\frac{p_{i}}{1-p i}\right)=\mathrm{Zi}=\mathrm{Li}=1 \mathrm{n}=\beta_{0}+\beta_{1} x_{1+} \beta_{2} x_{2+\cdots} \beta_{n} x_{n}$

Where $\mathrm{P}_{\mathrm{i}}=$ the probability that $\mathrm{Y}=1$ (the event occurred or probability of growth);

$1-\mathrm{P}_{\mathrm{i}}=$ the probability that $\mathrm{Y}=0$ (the event does not occur or no affected);

$\mathrm{L}_{\mathrm{i}}=$ the natural $\log$ of the odds ratio or logit

$\beta_{\mathrm{i}}=$ the slope, measures the change in L (Logit) for a unit change in explanatory variables

$(\mathrm{X})$; 
Analysis of Mobile Phone Technology Usage in Farmer Situation: The Case of Sodo Zuria District, Wolaita Zone, Southern Nation Nationalities and Peoples' Region, Ethiopia

$\beta_{0}=$ the intercept. It is the value of the $\log$ odd ratio, $\frac{p_{i}}{1+p_{i}}$, when $\mathrm{x}$ or explanatory Variable is zero. Thus, if the stochastic disturbance term $\left(\mathrm{u}_{\mathrm{i}}\right)$ is taken into consideration the legit model becomes

$\mathrm{L}_{\mathrm{i}}=\beta_{\mathrm{o}}+\beta_{1} \mathrm{X}_{1}+\beta_{1} \mathrm{X}_{1}$ $+{ }_{n} X_{n} \cdot+U_{i}$

In this study, the above econometric model will be used to analyze the data. The model was estimated using the interactive maximum livelihood estimation procedures. This estimation procedure yields unbiased, efficient and constant parameter estimation.

For this research descriptive statistics is one of the techniques were used to summarize the data collected from the sample respondents such as Frequency, table, mean, median, standard deviation, percentages and also inferential statistics like T-test and Chi-square test were used for comparing users and non-users of mobile phone technology for dissemination of agricultural information in various explanatory variables. SPSS-16 .0 was used for running models and calculation to synthesize the values.

\section{RESULT AND DISCUSSION}

\subsection{The Status of Mobile Phone Technology Usage in Farmer Situation}

Table2. The status of mobile phone technology usage in farmer situation $(n=120)$

\begin{tabular}{|c|c|c|c|}
\hline Variable & Mobile phone users & Mobile phone non users & Total \\
\hline Mobile phone technology usage & $34(28.3 \%)$ & $86(71.7 \%)$ & $120(100 \%)$ \\
\hline$X^{2}$ & $=22.533$ & & P-Value $=000 * * *$ \\
\hline
\end{tabular}

Note: *** Significant at $1 \%$ probability level

Source: Own survey

In table2, from total sampled households interviewed, 34 were mobile phone technology users and 86 were non-mobile phone users. This accounts mobile phone technology users are (28.3\%) and nonusers of mobile phone technology also accounts $(71.7 \%)$ of the total households. The $\mathrm{x}^{2}$-test, $(\mathrm{p}<0.000 * * *)$ shows that there was statistical significance between mobile phone technology users and nonusers of the two groups at $1 \%$ probability level in the study area. As the table above indicated that in SoddoZuria Woredamost of the households are non-user of mobile phone technology in farmers' situation.

\subsection{Determinants of Mobile Phone Usage in Farmer Situation}

Table3. Parameter estimates of the logistic regression model $(n=120)$

\begin{tabular}{|c|c|c|c|c|c|c|}
\hline $\begin{array}{l}\text { Dependent } \\
\text { Variable }\end{array}$ & Explanatory Variables & Coefficients(B) & Std. Error & Wald & Sign. & $\{\operatorname{Exp}\}(B)$ \\
\hline \multirow{19}{*}{$\begin{array}{c}\text { Mobile } \\
\text { phone } \\
\text { technology } \\
\text { usage }\end{array}$} & Sex & -0.203 & 0.561 & 0.131 & 0.717 & 0.816 \\
\hline & Age & 0.291 & 0.067 & 18.700 & $0.000 * * *$ & 1.338 \\
\hline & Family Size & -0.673 & 0.333 & 4.085 & $0.043 * *$ & 0.510 \\
\hline & Education Level & 15.738 & 1.394 & 0.000 & 0.991 & 6.838 \\
\hline & Total Annual Income & 0.002 & 0.000 & 24.199 & $0.000 * * *$ & 1.002 \\
\hline & Farm Size & 5.826 & 1.165 & 24.987 & $0.000 * * *$ & 338.96 \\
\hline & Livestock Holding & 21.312 & 2.513 & 0.000 & 0.993 & 1.803 \\
\hline & Cost of Mobile & 0.019 & 0.004 & 24.199 & $0.000 * * *$ & 1.019 \\
\hline & Tele Service & -0.496 & 0.410 & 1.465 & 0.226 & 0.609 \\
\hline & Mobile use training & -1.520 & 0.451 & 11.358 & $0.001 * * *$ & 0.219 \\
\hline & Credit Access & 0.610 & 0.675 & 0.815 & 0.367 & 1.840 \\
\hline & Market Access & -1.073 & 1.089 & 0.971 & 0.327 & 0.342 \\
\hline & Cosmopoliteness & 0.613 & 0.409 & 2.243 & 0.134 & 1.846 \\
\hline & Mobile phone Ownership & -0.357 & 0.424 & 0.708 & 0.400 & 0.700 \\
\hline & Membership of Association & -0.130 & 0.456 & 0.081 & 0.776 & 0.876 \\
\hline & Access to Agri-info. & 0.282 & 0.491 & 0.330 & 0.566 & 1.326 \\
\hline & Achievement Motivation & 2.491 & 0.893 & 13.893 & $0.001 * * *$ & 12.071 \\
\hline & Info.Seeking behavior & 23.436 & 1.798 & 4.823 & $0.090 *$ & 1.508 \\
\hline & $\begin{array}{l}\text { Attitude toward Mobile } \\
\text { phone }\end{array}$ & 0.762 & 0.516 & 2.559 & 0.278 & 0.467 \\
\hline
\end{tabular}

Note: ***, ** and $*$ Significant at $1 \%, 5 \%$ and $10 \%$ probability level respectively.

Source: Own survey, 2014

International Journal of Research Studies in Biosciences (IJRSB) 
In the study, nineteen variables were used. Based on the model result in Table 3 out of twenty variables, nine (Age, family size, education level, total income ,farm size, cost of mobile, mobile use training, information seeking behavior and achievement motivation)of them were statistically significant in the model while the rest were not significant at $(\mathrm{P}<0.10)$ probability level. More over in the model results variables such as family size, total annual income, farm size, telecommunication service, mobile phone use training, market access, mobile ownership and membership to association were found negative while the remaining had a positive sign of association with mobile phone technology usage in farmers' situation in the study area.

The significant variables included age, family size, education level, total annual income, farm size, cost of mobile, mobile phone use training, achievement motivation and information seeking behavior and nevertheless, the rest were in significant variables. The interpretations of the explanatory are given below.

Age: The variable is significant at $(\mathrm{p}<0.1)$ and positively related with farmers usage of mobile phone technology. This implies that mobile phone technology usage in farmers' situation might be increase when the age got increase and the interest of farmers also increase to use the mobile phone to their agricultural information dissemination. The odds ratio of 1.495 shows that under constant condition, the odds in act of kindness of the use of mobile phone technology in farmers' situation increase by a factor of 1.495 as the age of the house hold increase by one year.

Family Size: The variable is significant at $(\mathrm{p}<0.001)$ and negatively related with mobile phone technology usage in farmers' situation in the study area. The result is consisting with the hypothesis in that those farmers who have more number of children may have the probability of not having mobile phone. In other words the sampled household who have more number of family members have the probability to feed his/her family members than buying mobile phone for seeking agricultural information through it. The odds ratio of 0.510 indicates that under constant assumption the odds in favor of the mobile phone technology usage in farmers' situation decreases by a factor of 0.510 as the number of family members increases by one unit.

Total Annual Income: The variable is significant at $(\mathrm{p}<0.1)$ and negatively related with mobile phone technology usage in farmers' situation in the study area. The result is consisting with the hypothesis in that those farmers who have less annual income may have the probability of not having mobile phone. The odds ratio of 0.668 indicates that under constant assumption the odds in favor of the mobile phone technology usage in farmers' situation decreases by a factor of 0.668 as the annual income increases by one unit.

Farm Size: Availability of appropriate farm size is highly important for farmers to increase their agricultural production and productivity and more over to adopt new technology for their agricultural information. Farm size was negatively related to mobile phone technology usage in farmers' situation in the study area and significant at $(\mathrm{p}<0.1)$ probability level. This revealed with the hypothesis and the negative sign indicates that non-using of mobile phone decrease as the farm size increase. The odds ratio of 0.740 indicates that the availability of farm size implies that, other things being constant, the odds in favor of the mobile phone technology usage in farmers situation increase by a factor of 0.740 as farm size increases by one unit.

Cost of Mobile: The variable is significant at $(\mathrm{p}<0.1)$ and positively related with mobile phone technology usage in farmers' situation in the study area. The result is consisting with the hypothesis in that those farmers who have less annual income may have the probability of not having mobile phone. The odds ratio of 1.530 indicates that under constant assumption the odds in favor of the mobile phone technology usage in farmers' situation decreases by a factor of 1.530 as the annual income increases by one unit.

Mobile Phone Use Training: The model result indicates that it affects the decision of farmers to use mobile phone technology for agricultural information dissemination negatively and significantly at $(\mathrm{P}<0.001)$ probability level. This means that as the member of the households don't participate in mobile phone use training and other information services they don't acquire sufficient knowledge and skill about the use of mobile for agriculture. The odds ratio of 0.219 indicates that under constant assumption the odds in favor of the mobile phone technology usage in farmers' situation decreases by a factor of 0.219 as the training obtained by households increases by one unit. 
Achievement Motivation: The variable is significant at $(\mathrm{p}<0.001)$ and positively related with mobile phone technology usage in farmers' situation in the study area. The result is consisting with the hypothesis in that those farmers who have high achievement motivation may have the probability of having mobile phone. The odds ratio of 12.071 indicates that under constant assumption the odds in favor of the mobile phone technology usage in farmers' situation decreases by a factor of 12.071 as the achievement motivation experience increases by one unit.

Information Seeking Behavior: The variable is significant at $(\mathrm{p}<0.1)$ and positively related with mobile phone technology usage in farmers' situation in the study area. The result is consisting with the hypothesis in that those farmers who have high information seeking behavior may have the probability of having mobile phone. The odds ratio of 1.508 indicates that under constant assumption the odds in favor of the mobile phone technology usage in farmers' situation decreases by a factor of 1.508 as the information seeking behavior of the farmers increases by one unit.

\section{CONCLUSION}

Moreover, the results showed that nearly $28.3 \%$ of the sampled household farmers in Sodo Zuria Woreda use the mobile phone but $71.7 \%$ were non-users of mobile phone technology as a means to access agricultural information. Moreover, farmers use mobile phone on a daily basis to communicate with relatives rather than to obtain agricultural information.

The model Result shows that family sizes of sample respondents was significant and negatively affects the mobile phone technology usage in the study area. This could result from the sampled household who have more number of family members have the probability to consume more to feed his/her family members rather than buying mobile phone for seeking agricultural information through it in the study area in farmers situation.

The result indicates that total annual income is positively related to mobile telephony. This is logical, as mobile phones are expensive and only the small-scale farmers with much total annual income are likely to consume them. Farmers who have low income level could not afford mobile phone technology usage for their farming activities.

The result indicates that mobile phone users on average have large farm size than that of mobile nonusers. The finding indicates that households with more access to land are likely to use mobile technologies more, particularly purchasing inputs as they have supportive, economic basis for the choice of using the technology.

Cost of mobile was found highly significant impact on mobile phone technology usage in farmers' situation in the study area. Ethiopia has witnessed rapid penetration of telephone technologies and access to other information and communications technology (ICT) services in the last five years. By the end of 2012, Ethiopia's mobile penetration had reached over 18million subscribers (nearly $21 \%$ penetration). However, fixed-line penetration remains less than $1.5 \%$, and internet and data users account for a mere $1.1 \%$ of the population. This implies that even if there is high opportunities to enjoy the benefit of the mobile phone technology farmers' were not realized it in the study area.

Mobile use training was significant with dependent variable mobile phone technology usage in farmers' situation in the study area. It has been observed that those who do not have any formal literacy are able to access the mobile phone interface by memorizing the signs or symbols instead of the letters the knowledge they got from their relatives. This at least suffices to be able to perform basic operation of the phones.

Information seeking behavior of farming households was significant with the dependent variable mobile phone technology usage in farmers' situation in the study area. During the my own survey 2014, most of the farmers reported that they use mobile phones mainly for social communication but later they have increasingly started using it to get connected with people like traders and other farmers who have agricultural activities related information. Most of the small farmers reported that there is some increase in convenience and cost savings from using their mobile phones as basic communication devices to seek information, such as input availability or on market prices.

\section{RECOMMENDATIONS}

The results of this study revealed that age, family size, total annual income, farm size, mobile use training, achievement motivation and information seeking behavior of the faming households were significantly affect at $(1 \%, 5 \%$, and $10 \%)$ probability level dependent with variable mobile phone 
Analysis of Mobile Phone Technology Usage in Farmer Situation: The Case of Sodo Zuria District, Wolaita Zone, Southern Nation Nationalities and Peoples' Region, Ethiopia

usage in farmers' situation in the study area. The following policy implications were forwarded for each significant explanatory variables included in this work as follows.

The result of this study indicates that age of the farming households positively and significantly affect the mobile phone technology usage in farmers' situation in the study area. This is the fact that the people in whose age lie in the productive (20-45 years old) range were highly involved with in any development actively in any country. Hence, the study recommends that government should increasing mobile phone and mobile phone based services enhances the availability to knowledge and information and will further help in improving awareness, education, better adoption of technology, reduced transaction costs, better market efficiencies, etc.

- The government should access mobile phone for usage of agricultural information by age group specific targeting.

- Addressing mobile technology usage by giving priority for large house hold size.

- Creating rural interventions for income generation for lower income households.

- Land distribution can be revisited and any available arable land that is not under cultivation could be redistributed to willing farmers to increase their land size which in turn might increase their mobile phone usage.

- For cost of mobile phone problem ETC should initiate and open mobile phone centers for farmers at least in the village level and may sell mobile phone at cost price.

- Training should be given by ETC and MoA how to access and use mobile phone usage for agroinformation.

- FTC may include a training module on Achievement motivation benefits and capabilities.

- In meetings of farmers, the Keble information officer may ignite the interest of farmers to gather agro-information from all possible sources that they may have access to as it would help them to increase their mobile phone usage and encourage non-users to become users. Bed accommodation

\section{REFERENCES}

[1] Aker, J. C. 2010. Information from markets far and near: Mobile phones and agricultural markets in Niger. American Economic Journal: Applied Economics, 2, 46-59.

[2] Aker, J. C. 2011. Dial "A" for agriculture: a review of information and communication technologies for agricultural extension in developing countries. Agricultural Economics, 42 (6) :631-647.

[3] Aker, Jenny C. and Isaac Mbiti. Summer 2010.Mobile phones and economic development in (ICTs) for the small-scale farmers in Zambia. Library Hi Tech, 23(3): 414 - 424-572

[4] Feder, G., R.E. Just, and D.Zilberman, 1985. Adoption of Agricultural Innovation In developing countries: A survey of World Bank staff working Papers, No.542.The World Bank, Washington DC.

[5] Gujarati, D.N., 1998. Basic Econometrics. Second edition. McGraw Hill Co.: New York.

[6] Hosseini, S.J.F., Niknami , M. and Chizari, M., 2009.To determine the challenges in the application of ICTs by the agricultural extension service in Iran. Journal of Agricultural Extension and Rural Development, 1(1): 27-30.

[7] ITU (International Telecommunication Union), 2009.Information Society Statistical Profiles 2009. Africa, ITU Telecommunications Development Bureau. ITU : Geneva

[8] Samuel, J, Shah, N., and Hadingham, W., 2005. Mobile communications in South Africa, Tanzania and Egypt: results from community and business surveys pp. 44-52. In Africa: The Impact of Mobile Phones. The Vodafone Policy Paper Series No.3. Vodafone Group.

Citation: Michael Heliso \& Sundaraa Rajan, "Analysis of Mobile Phone Technology Usage in Farmer Situation: The Case of Sodo Zuria District, Wolaita Zone, Southern Nation Nationalities and Peoples' Region, Ethiopia", International Journal of Research Studies in Biosciences (IJRSB), vol. 7, no. 1, pp. 1-7, 2019. http://dx.doi. org/10.20431/2349-0365.0701001

Copyright: (C) 2018 Authors. This is an open-access article distributed under the terms of the Creative Commons Attribution License, which permits unrestricted use, distribution, and reproduction in any medium, provided the original author and source are credited. 